\section{LA DIALÉCTICA DEL AMOR-ODIO EN EMPÉDOCLES Y SCHOPENHAUER ${ }^{1}$}

\author{
David Emilio Morales Troncoso \\ Universidad Diego Portales (Chile) \\ david.morales@udp.cl
}

\begin{abstract}
The dialectical thinking can be described as a way of understand an idea which involves the necessary coexistence of the contrary. In the philosophy of Empedocles and Schopenhauer we can find a similar sense of dialectic thought, that is recognized by the last and points to the reevaluation of the moral experience as the ground of representation of the motion of the world of the life.
\end{abstract}

KEY WORDS: Empedocles; Schopenhauer; dialectic; cosmology; moral.

\section{Prólogo}

El estilo de pensar el ente natural finito como un núcleo de tensiones dinámicas, tiene una premisa fundamental en el pensamiento del filósofo siciliano Empédocles (c. 444 a. C.), que representa sus intuiciones cosmológicas como una pluralidad de 4 elementos materiales junto a dos categorías psicológicas como causas motrices -el amor y el odio: filía kai neîkos-. La influencia alternada de estas fuerzas motrices sirve para explicar las tendencias opuestas, de aversión y de unión, pasando también desde ser múltiple a lo uno, y viceversa, disgregándose de lo Uno para retornar a lo elemental determinado, en un ciclo temporal semejante al que señala el célebre fragmento de Anaximandro.

Por otra parte, uno de los paralelos más interesantes de la filosofía, que se hace cargo de intuir dialécticamente el vaivén cósmico de unión-separación en la naturaleza, vive en el pensamiento de Arthur Schopenhauer. Este original filósofo, cuya intuición central y cosmológica es la presencia inmanente de una Voluntad en la Naturaleza, identificada con la cosa en sí kantiana y descrito también como un impulso ciego y libre, desarrolla una interesante analogía, paralela a las antiguas visiones de Empédocles, pues lo que para éste era el poder de la odiosa separación

\section{THE LOVE-HATE DIALECTICS BY EMPEDOCLES AND SCHOPENHAUER}

RESUMEN: El pensamiento dialéctico se puede describir como un modo de concebir una idea que involucra la necesaria coexistencia de su contrario o complementario. En las filosofías de Empédocles y en Schopenhauer se da una semejanza en este sentido, que es advertida por este último y que apunta a la reivindicación de la experiencia moral como soporte de una representación del devenir del mundo de la vida.

PALABRAS CLAVE: Empédocles; Schopenhauer; dialéctica; cosmología y moral.

será entendido por el alemán como un principio natural de la individuación de todo ente.

\section{EMPÉDOCLES Y EL PODER DE LA INDISTINCIÓN}

Las grandes fuerzas de la Naturaleza son quizás los enigmas más difíciles de abordar por la racionalidad filosófica, mas aún cuando la perspectiva adoptada es un pensamiento que considera a la realidad humana como una parte orgánica de ella misma, vale decir, que en la estructura del sujeto particular se encuentra operando un dinamismo análogo al todo natural.

En este predicamento uno de los relatos más verosímiles que se han tejido en la filosofía antigua, sobre el eterno flujo del devenir de los entes, es la tentativa de explicarnos el misterio del Ser haciendo un uso especial de categorías antropológicas y éticas. Es el caso que me propongo analizar, pues dentro de la multitud de matices del lenguaje de las pasiones, parece natural proponer que los dos grandes polos en que se agita el Alma del mundo, como también el alma humana individual, son las emociones básicas del amor y del odio, en una tensión dialéctica constante y 
alternada de fenómenos de generación y de destrucción de los entes naturales que entran al juego de lenguaje de la representación filosófica.

En efecto, según señala Anaximandro en su célebre fragmento, los entes particulares purgan la injusticia de su separación del todo primordial según el orden del tiempo, y el fenómeno sucesivo del nacimiento y la disolución, parecen tener en estas pasiones - del amor y el odio- sus causas primordiales.

Así lo parece sugerir el primer verso con que amanece la poesía de Occidente:

Canta oh diosa, la cólera del pélida Aquiles, cólera funesta que causó infinitos males a los aqueos y precipitó al Hades muchas almas valerosas de los héroes².

Por otro lado, el hexámetro poético es también el vehículo preferido de la temprana filosofía de la naturaleza, que surge a inicios del siglo VI tanto en Asia Menor como en el sur de Italia. De esta última región, en la volcánica Sicilia, surge la figura enigmática de Empédocles de Agrigento, mezcla de filósofo, mago y líder espiritual. Se sabe que floreció cerca del 444 a.C. y por su situación histórica puede ser llamado con justicia un epígono del período cosmológico de la filosofía, dado que su sistema es una especie de sincretismo, en donde conviven perfectamente entrelazadas ciertas creencias órfico-pitagóricas sobre el destino del alma, junto al típico discurso verosímil desarrollado por los cosmólogos de la época ${ }^{3}$. De tal modo que su pensamiento gravita entre la física teórica, en este caso pluralista de causas, y una psicología individual orientada a la purificación, sin hacer gran diferencia entre estos planos físico-psíquicos, ni distinciones entre las causas, como si lo hace Aristóteles.

La referencia a Aristóteles no es casual, dada la decisiva influencia del libro I de su Metafísica en la historia de la interpretación de los filósofos pre-platónicos, y de nuestro Empédocles en particular ${ }^{4}$. Esta valoración histórica es advertida por Schopenhauer en sus Fragmentos sobre la Historia de la Filosofía, y reacciona de este modo. Cito:

Como carácter fundamental de Aristóteles se podría señalar una enorme sagacidad unida a la circunspección, dotes de observación, carácter polifacético y falta de profundidad. Su visión del mundo es plana, aunque sagazmente trabajada...Su metafisica es en su mayor parte, un hablar aqui y allá sobre los filosofemas de sus predecesores, a los que critica y rebate desde su propio punto de vista, la mayoría de las veces en virtud de sentencias aisladas de aquellos, sin penetrar verdaderamente en su sentido, sino más bien como quien rompe la ventana desde afuera... siendo incapaz de seguir cualquier curso de pensamiento hasta el final: pues justamente en esto consiste el pensamiento profundo.

Parecen mezquinas estas irónicas palabras del pensador de Frankfurt contra Aristóteles, pero lo cierto es que llevan algo de cierto, ya que el consabido lenguaje tetra-causal del macedonio termina imponiendo, históricamente, ciertas condiciones de inteligibilidad para el pensamiento del pasado, en este caso, sobre la noción misma de causalidad.

Por otro lado, debo reconocer que no podemos renunciar del todo al aparato conceptual de las cuatro causas de Aristóteles, para repensar el pensamiento de Empédocles, pero la observación anterior de Schopenhauer nos advierte de que al menos debemos tomar cierta distancia crítica cuando este dispositivo desvia al pensamiento hacia otros asuntos, puesto que Empédocles propone, en su pensamiento cosmológico, una pluralidad de raíces elementales para descifrar el enigma ciclo del tiempo.

En el siguiente pasaje se describe de modo conciso el difícil tema de su cosmogonía:

"Su sistema es en extremo complejo. El elemento pasivo se halla representado por las cuatro raíces (rizomas) o cuerpos elementales: fuego, aire, tierra y agua ${ }^{5}$, los cuatro elementos típicos de la filosofía griega posterior. Además hay dos causas movientes: el principio unificador, Amor (eros) o Afrodita, y el principio separativo, Discordia (eris) o Ares; el proceso cósmico es un ciclo siempre repetido en el que cada una de estas causas (motrices) prevalece alternativamente. Este proceso comienza con el Esfero inmóvil en el que los cuatro elementos se encuentran perfectamente mezclados bajo el dominio absoluto del Amor. Este Sphairos de Empédocles es una concepción estrechamente emparentada con el huevo del mundo de los órficos, y la idea es una mezcla perfecta o equilibrio de los elementos opuestos (...) el período siguiente del ciclo se produce cuando la Discordia comienza a ganar terreno gradualmente hasta que llega a un estado de perfec- 
ta separación de los elementos. Entonces vuelve a predominar el Amor, hasta que finalmente el ciclo retorna a su punto de partida, es decir, a la perfecta mezcla de los elementos dentro de la Esfera. Sólo en las etapas intermedias, cuando no hay ni completa separación, ni completa fusión de los elementos, pueden existir los entes particulares y el Universo tal como lo conocemos" (A. H. Armstrong, Introducción a la Fil. Antigua, Eudeba, 1982, p. 35).

Este ajustado resumen sintetiza de modo notable las difíciles cuestiones relacionadas con la sucesión y la resolución de los momentos del ciclo cósmico de Empédocles, dado que, siendo coherente con la intuición mítica del eterno retorno de lo mismo, termina cerrando un movimiento del tiempo natural con el inicio de otro ciclo, al estilo de un gran año cósmico que se repite por toda la eternidad del mundo.

Entretanto, apreciamos que en la teoría de Empédocles, resumida más arriba, se encuentra una versión sin precedentes de dualismo físico y moral a la vez, cuestión que en otro momento del pensar griego no habría sido posible. Este aspecto dialéctico de su pensar se observa también en la coexistencia de los factores psíquicos que encontramos en su explicación sobre la mecánica del mundo físico. En efecto, junto con las cuatro raíces -o rizomas- elementales: el fuego, aire, tierra y agua, se añaden dos fuerzas motrices, que son la causa de sus múltiples combinaciones en el universo cósmico. Estas causas móviles están representados por la Amistad (o amor = eros), y su contrario, el Odio (o discordia = eris). Estos seis factores físico-psíquicos se encuentran interrelacionados en el sistema, siendo éstos la causa del movimiento combinatorio de aquellos. Cuando se aman a sí mismos, se reúnen los elementos, y su causa es la separación de lo otro; luego cuando se mezclan con sus complementarios, la amistad comienza produciéndose una unión provisional, auspiciada por eros. En otro momento teórico, cuando los elementos mezclados en uno se disipan, ya se odian entre ellos, ya van generando otras reuniones afines entre las raíces, reconocibles en los cuatro elementos que van rotando y girando según el predominio de la amistad o del odio.

Consecuentemente reconocemos, en esta original visión cosmológica del devenir, el Microcosmos humano y el Macrocosmos físico, gobernados por los mismos principios orgánicos, y que no son sólo las materias pasivas. De tal suerte, en la sucesión del devenir de las cosas generadas en el mundo, y que se dan a partir de combinaciones con los elementos básicos, las emociones originales, de la inclinación y el rechazo, se proyectan también hacia el orden del cosmos para explicar la unión y la separación permanente de los seres generados en el tiempo, ya sea en una amistosa concentración o en una odiosa repulsión natural. De forma alternada e interminable entonces, lo semejante consigo mismos alterna con lo desemejante para producir los múltiples individuos y, recursivamente, los elementos vuelven a reunirse consigo mismos al cabo del ciclo vital que cumple cada organismo multicelular, que se representa como una porción determinada de la mezcla de los elementos, en un ir y venir de lo uno a lo múltiple y viceversa, para continuar la historia del cosmos.

Para ilustrar los anteriores conceptos, que corresponden a una interpretación global de diversos fragmentos, cito a continuación partes del famoso fragmento 17, que reúne en pocos párrafos una versión inteligible de la compleja filosofía de Empédocles. Cito:

Debo anunciarte una doble narración. Una vez, una sola cosa creció a partir de muchas, y, otra vez, se separó para ser muchas a partir de una. Doble es la generación de los seres mortales, y doble su destrucción. Un par (de generación y destrucción) nace y muere por la concurrencia de todas las cosas; (5) el otro crece y, luego, se disipa cuando ellas se separan de nuevo. Y ellos no dejan nunca de cambiar de lugar incesantemente, de este modo; unas veces confluyendo todos en uno por medio del Amor, y otras veces separándose cada uno por el odio de la Discordia. Así, en tanto que se habituaron a que uno crezca a partir de muchos,(10) y a que uno se divida, a su vez en muchos de nuevo, de este modo están sometidos al devenir y no tienen vida estable; pues en tanto que no cesan nunca de confluir y separarse alternativamente, existen para siempre, inmutables en su camino cíclico.

Pero vamos, escucha mi discurso, ya que el aprendizaje acrecienta la sabiduría.

(15) Como ya dije antes, cuando estaba estableciendo los confines de mi discurso, yo te contaré una doble narración. Una vez, una sola cosa creció a partir de muchas, y otra vez se separó para ser muchas a partir de una: el fuego, el agua, la tierra y la inconmensurable altura del aire, y la funesta Discordia, separada de éstos e igual en cualquier respecto (20) y el Amor entre ellos, semejante en longitud

ARBOR CLXXXVI 742 marzo-abril [2010] 311-319 ISSN: 0210-1963

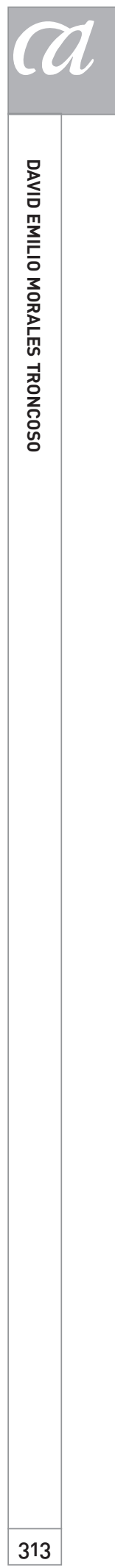


y profundidad. A él tienes que mirarlo con la mente, no te quedes inmóvil con ojos de asombro: es a él quién se considera innato en los miembros de los mortales, y es por él por quién los hombres piensan amorosos pensamientos y realizan acciones pacíficas, llamándolo por los nombres de Gozo y Afrodita (25). Ningún mortal lo ha visto cuando gira en derredor de ellos (es decir, de los elementos de la Discordia); pero escucha tú el orden no engañoso de mi discurso. Todos ellos son semejantes y de la misma edad, pero cada uno es señor de un distrito diferente y cada uno posee su propio carácter, y prevalecen, alternativamente, conforme el tiempo gira trazando su círculo.

(Cf. W. K. C. Guthrie, Historia de la filosofía Griega, Vol. I, Gredos, 1984, p. 164).

En esta visión sinóptica de la procesión del Ser de Empédocles se presentan sus intuiciones proto-cósmicas, con una clara noción dialéctica de las relaciones entre lo uno y lo múltiple, ya que junto con la absoluta irreductibilidad del amor en el odio y viceversa, encontramos un ejemplo extraordinario de pensamiento dialéctico; un pensar que, siendo pluralista en su referencia a las causas de las sustancias, exige del lector una perspectiva holística del ser, vale decir una visión que considera suspender por un momento el juicio analítico -de herencia aristotélica-, para dejarse llevar por el poder de la indistinción, que es también un nombre para el método de la dialéctica del ser, algo que justamente para Aristóteles es una cualidad criticable del pensamiento de Empédocles.

En efecto, el hábito crítico de distinguir los aspectos físicos de la realidad, no siempre es útil como instrumento de comprensión profunda de los hilozoistas, pues los conceptos aristotélicos del ser pueden causar la obnubilación del entendimiento, pues su método separa en el concepto lo que en la naturaleza está unido. Esto ocurre toda vez que las fuerzas cósmicas son pensadas con el dispositivo automático de su análisis. Algunos tópicos importantes que se recuperan utilizando el poder de la indistinción dialéctica son:

1. La percepción hilozoísta del mundo físico; actitud intelectual que siendo remanente del pensamiento mítico arcaico, piensa a todas las materias primas como sustancias animadas mediante fuerzas metafísicas. En el caso de la dialéctica amor-odio, rinden una intuición plena de simbolismos que Empédocles despliega en una explicación filosófica, que considera también a los elementos materiales conllevando cualidades móviles intrínsecas, pues, los elementos físicos contienen una naturaleza semoviente propia y por otra parte las causas motrices amor-odio también conservan una vinculación con el comportamiento corporal en sus fragmentos, como por ejemplo cuando se refiere que el amor se extiende en longitud (cf. fragmento 17,20$)$.

2. El poder de la indistinción nos permite asemejar a la vida orgánica de los animales, con la vida "inorgánica" de los seres inanimados, que desde su poder elemental sostienen los fundamentos de todas las cadenas de vida orgánica, que son dependientes de un oscuro trasfondo inorgánico. Basta con el ejemplo de la vida vegetal que provee de base para toda la cadena trófi$\mathrm{ca}$, y que es la que sostiene un puente de continuidad con lo elemental, realizando el milagro alquímico de transformar la luz del sol, la firmeza de la tierra, el espacio del aire y la humedad líquida del agua, en las condiciones de posibilidad de la vida del vegetal, vinculando el concepto de Hyle con el de Zoé como dos aspectos de una realidad que tiene relación de continuidad; este argumento tiene sus raíces en una comprensión ecológica profunda y en el sentido de ser una cosmovisión de sistemas interdependientes.

3. Más interesante aún es el factor explicativo de las inclinaciones humanas, pues la visión de Empédocles, como ya está dicho, relaciona sin resistencias a la física con la psicología -es el caso de las causas motrices del amor y el odio, motor dialéctico del mundo físico y psíquico- y que tiene un campo de interesantes aplicaciones en la psicología individual y en la intuición mítica, capaz de generar alegorias de lenguaje simbólico de gran eficacia especulativa (por ej. la astrología racional como sprachspiel).

4. Por último, y como una evocación panteista, podemos decir que es el propio cosmos el que despliega su autoconciencia por la boca de los poetas. Es el caso de la inspiración de Hesíodo, quizás el mejor ejemplo de un logos cósmico que revela su verdad en virtud del rapto de las musas divinas. Sin embargo fue Empédocles el más osado, toda vez que se consideraba él mismo un ser divinizado que desde su apoteosis 
miraba hacia el mundo de los hombres derramando su saber cósmico ${ }^{6}$. Finalmente lo importante aquí es que el poder de la indistinción, que actúa también entre mythos y logos, nos conduce a reconocer la tremenda capacidad representacional de ambos dispositivos discursivos que conviven en Empédocles en un mismo soporte psíquico.

A modo de aclaración, quisiera volver a señalar que el poder de la indistinción, sugerida también como una actitud anti o pre-aristotélica, posibilita tener un pensamiento más propiamente dialéctico, en donde lo uno y lo otro son factores indisolubles e irreductibles entre sí, como lo son el amor y el odio en el cosmos, a la hora de pensar humanamente la realidad del hombre, del mundo y de lo absoluto.

\section{La filosofía tRascendental como paradoja del PENSAMIENTO EN SCHOPENHAUER}

De acuerdo con Schopenhauer (1788-1960) su filosofía pesimista tiende un puente entre la intuición (que es verdadera pero lamentablemente incomunicable) y el conocimiento conceptual y abstracto (que es comunicable pero falso). No obstante esta paradoja, la filosofía es una empresa que comienza con la experiencia vivida, cuestión que también alcanza a la intuición metafísica.

Aquí también encontramos un caso notable de escritura metafórica pero con declarado afán de esclarecimiento, en la medida que lo permita la escritura, cito al autor:

El filósofo auténtico buscará sobre todo claridad y precisión y se esforzará siempre en parecer, no un turbio y movedizo torrente, sino más bien un lago de Suiza, que por su sosiego tiene en la mayor profundidad gran claridad, siendo la claridad precisamente lo que hace visible la profundidad (Cf. Metafísica de Las Costumbres, Ed. de R. Aramayo, Trotta, 2001, p.86).

En esta atmósfera alpina y filosófica el pensador conquista la cima de una consciencia superior, que tempranamente en su vida denomina, la consciencia mejor.

Dicha consciencia, que habría logrado situarse más allá del tiempo y del espacio, nos conduciria hasta un lugar en donde no hay personalidad ni causalidad algunas. Para ella no cabe la distinción entre sujeto y objeto, por no haber ni siquiera sitio para ninguna divinidad (Idem, Aramayo, p. 89).

Trataré de mostrar en lo siguiente en que puede consistir esta consciencia orgánica de ser en el mundo y luego ver en que se asemeja Schopenhauer al pensar del filósofo siciliano.

Debo partir señalando que el pensamiento filosófico de Schopenhauer, según el mismo reconoce, estuvo orientado principalmente a buscar un remedio eficaz contra el sufrimiento de la vida, y por eso su punto de partida no es el de la admiración del ser, sino la clara intuición de la pobre condición humana, ya que según su opinión, si el ser humano fuera feliz, no tendría ninguna necesidad de pensarse. Esta peculiaridad está bien descrita por Max Horkheimer:

El ser sumo, supremamente real, el ser esencial metafísico al que dirigen la mirada los filósofos desde el cambiante mundo de las cosas existentes, no es al mismo tiempo el bien, y los grados de realidad no son grados de perfección; la mirada que contempla lo positivamente infinito, lo incondicionado, no enseña lo que ha de hacerse: es imposible invocar la autoridad del ser si se quiere ir a parar a una acción conveniente...Para Schopenhauer, el bien es mucho más lo efímero, el pensamiento y la apariencia que lo que se reproduce perennemente (F. Savater, "Schopenhauer", Hia. de la ética, V. Camps ed., Crítica, 1989, p. 503).

Esta perspectiva claramente pesimista se comprende mejor desde el concepto central de su metafísica, que es el de Voluntad (Wille). Comenta Savater:

"Esta noción compleja hasta el equívoco abarca la entraña del mundo y también su calificación...es el ímpetu universal de autoafirmación, es un ciego afán de ser que late tras la diversidad de las apariencias y que se alimenta inacabable e inexplicablemente de sí misma (deseo de deseo?): la cosa en sí kantiana, que era un postulado epistemológico de la razón pura, aquí se convierte en una fuerza demoníaca...y en el hombre, la manifestación de esa voluntad, que le constituye dentro de los contornos de su destino individual, es el egoísmo" (Idem, 504).

Para aclarar un poco esto revisemos brevemente su itinerario filosófico pues, ¿Cuál es ese descubrimiento del que 
tanto se preció Schopenhauer? Lo que él reconoce como tal es el haber despejado la gran incógnita kantiana sobre "la cosa en si", trasfondo del mundo fenoménico según la perspectiva trascendental kantiana. En efecto, para Schopenhauer como para Kant el mundo que conocemos es puro fenómeno: pues el mundo de nuestro conocimiento es nuestra representación del mundo, tal como el sujeto se lo representa a través de las formas subjetivas de la percepción, que son el tiempo y el espacio, y que en el entendimiento aparecen ligadas por una categoria necesaria, el principio de razón suficiente o de causalidad del conocer?. Este complejo asunto, de definir las fronteras representacionales del fenómeno y su relación con la fuerza de la voluntad de vida, forma parte esencial del programa teórico de su obra mayor Die Welt als Wille und Vorstellung.

Por otra parte, nos resulta evidente que la distinción entre ensueño y embriaguez que establece el joven Nietzsche en El Nacimiento de la Tragedia es tomada de la distinción schopenhaueriana entre representación y voluntad. Estos dos principios se derivan a su vez de la teoría del conocimiento kantiana, que considera que sólo conocemos el fenómeno y nunca la cosa en sí, ya que no nos podemos liberar de las condiciones de posibilidad de nuestro conocimiento.

De este modo, Nietzsche habla del mundo de la apariencia apolínea y Schopenhauer del mundo de la representación, para referirse a ese terreno meramente fenoménico y sujeto al principio de razón (tiempo, espacio y causalidad) en el que los hombres "normales" se mueven diariamente.

No obstante, para ambos la cosa en sí es cognoscible pero está libre de toda razón. La voluntad es un principio irracional, indeterminado, infinito (no está sujeto al espacio), eterno (no está sujeto al tiempo), independiente y único. Por otro lado, la Voluntad o el Uno primordial es el fondo místico de todo lo que existe; carece de la díada sujetoobjeto porque pone en evidencia que el mundo es uno y en él cada individuo se funde, se pierde, se olvida de sí y de todo lo que le es propio. No obstante las diferencias ambos reconocen que el fondo del mundo es irracional, que no existe una clara relación de causa y efecto, y es por esto que Schopenhauer habla de la voluntad como un continuo querer $\sin$ fin, sin más causa aparente que la motivación egoísta, que en el fondo sería una objetivación individual del devenir natural de la Voluntad infinita.
De alli que el hombre debe renunciar a su pretensión de comprender lo que está más allá de su representación, puesto que no es ningún ser especial, es sólo una fase de la objetivación de la voluntad, y sólo tiene una diferencia de grado con el resto de los seres orgánicos e inorgánicos, pues más allá de las fronteras de la representación sólo existe la voluntad. Cito a Schopenhauer:

Si se consideran las contadas ocasiones en que a lo largo de la Crítica de la Razón Pura y de los Prolegómenos, Kant saca un poco a la cosa en si de las tinieblas en que la mantiene, es para presentarla como responsabilidad moral dentro de nosotros y por tanto como voluntad...se advertirá entonces que yo, mediante la identificación de la voluntad con la cosa en sí, he puesto en claro y llevado hasta sus últimas consecuencias el pensamiento de Kant...pues el mito de la caverna de Platón, y el velo de Maya de los Vedas hindúes, serian imágenes equivalentes a los términos trascendentales de la cosa en si kantiana y a la voluntad schopenhaueriana ${ }^{8}$.

En tanto, la vida moral, trasunta un hondo pesimismo trágico y no transa con los términos de la moral de deberes kantiana, pues a su juicio: "no hay otro camino para llegar al fundamento de la ética salvo el empírico, es decir indagar si se dan acciones a las que debamos atribuir auténtico valor moral" tales como cualquier forma de altruismo o filantropía. Este punto de partida le hace ironizar con la escuela kantiana:

Puesto que la moral ha de habérselas con la conducta real del hombre y no con aprioristicos castillos de naipes, ante cuyos resultados ningún hombre inmerso en los graves apremios de la vida y al torbellino de pasiones, resultaría salvo, por lo tanto es comparable al querer apagar un incendio con una jeringuilla.

En su opinión, el formalismo legalista de Kant, que supone una autoridad trascendente a la inclinación se muestra insolvente para combatir a ese antagonista de la moral, que es el egoísmo. ¿Pero acaso existe de hecho algún principio que pueda contrarrestar la fuerza inmediata del egoísmo? $Y$ en efecto que lo hay, el principio contrapuesto a la preocupación particular por lo provechoso es la compasión (Mitleid), entendida como la apertura incondicionada hacia el otro y que a Schopenhauer se le antoja nombrar como el mayor misterio de la ética y objeto propio de la especulación metafísica, pues constituye su 
fenómeno primordial y originario. Y puesto que ya que se sabe que nuestra motivación principal para actuar es el egoísmo, por ello mismo propone adoptar "la ausencia de toda motivación egoísta como criterio de valor moral de las acciones" pues la compasión es un sentimiento que nos hace identificarnos con el dolor de aquello que no somos nosotros, ya sea hombres, animales o plantas; y dado que la vida es principalmente dolor y hastío, la compasión es

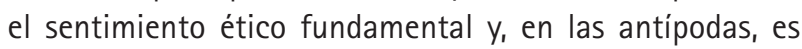
inmoral el que goza, aumenta o es indiferente al dolor ajeno.

De otra parte es la voluntad de la naturaleza, constreñida en un ser individual, la condición que permite la inmoralidad, puesto que esta tendencia naturalmente egoista esta fundada en el principio de individuación, que se revela como la causa más eficiente del mal moral, al motivar permanentemente la antipatía por la otredad. Así describe su propia experiencia:

En mi mismo observo que a veces contemplo a todos los seres con una cordial compasión, otras con gran indiferencia $y$, si se tercia, con odio, regocijándome del mal ajeno. Todo ello brinda muy claros indicios respecto a que poseemos dos modos de conocimiento diversos y contradictorios; uno con arreglo al principium individuationis nos hace ver a todo ser como algo que nos es totalmente ajeno y extraño, como un categórico No-Yo; en tal caso no podremos experimentar hacia ellos más que indiferencia, envidia, odio o malicia. En cambio, el otro modo de conocimiento, que yo quisiera denominar conforme al axioma védico tat-twan-asi (tu eres eso), nos hace ver a cualquier ser como idéntico con mi propio yo, por lo que su contemplación nos provoca compasión y afecto. El primer modo de conocimiento es el único que resulta demostrable y razonable; el otro constituye la puerta del universo y no posee refrendo alguno por encima suyo, suponiendo por ello el punto más abstracto y complicado de mi doctrina (Manuscritos berlineses, HN,III, 371; 1996c, 178, 189).

\section{A MODO DE CONCLUSIONES}

Pese al mezquino juicio de Schopenhauer sobre los méritos intelectuales del autor de la Metafísica, paradójicamente también se revela como un atento seguidor de esta tra- dición, pues en su diálogo libresco con los presocráticos sigue también el orden establecido por Aristóteles, así al menos en el tratamiento de estos temas en sus Fragmentos sobre la Historia de la Filosofía. En el siguiente texto encontramos finalmente su valoración definitiva de Empédocles desde su visión filosófica y sistemática, a la vez que expone y critica primero, los conceptos cosmológicos de Anaxágoras, -que propone una inteligencia ordenadora (nous) de múltiples partes similares- para luego ensalzar la lúcida dialéctica del amor-odio para dar cuenta del mundo como Voluntad de ser. Cito:

Empédocles en cambio, en lugar de innumerables homeomerías mantenía cuatro elementos de los que luego habrian de resultar las cosas como productos y no como eductos, según ocurria en Anaxágoras. El papel unificador y separador, esto es, ordenador del nous, lo desempeña en él filía kai neîkos, amor y odio. Esto es mucho más sensato. En efecto, el no recomienda la disposición de las cosas al intelecto (nous) sino a la voluntad (filia kai neikos), y las diferentes sustancias no son, como en Anaxágoras, meros eductos, sino productos reales. Si para Anaxágoras surgían en virtud de un entendimiento diferenciador, para Empédocles nacen de un impulso ciego, es decir, de una voluntad carente de conocimiento. Empédocles es, en fin, todo un hombre y su filía kai neikos se basa en un apercibimiento profundo y verdadero, Ya en la naturaleza vemos que las sustancias se buscan y rehúyen... Así filía kai neikos están realmente presentes en todas partes, y únicamente de acuerdo con las circunstancias aparecerá en cada caso la una o el otro. Conforme a ello, también nosotros mismos podemos en un instante tener amistad o enemistad con cada hombre que se nos acerca: la disposición a ambas cosas está ahí y aguarda las circunstancias. Sólo la prudencia nos ordena quedarnos en el punto medio de la indiferencia, aun cuando este sea al mismo tiempo el punto de congelación. Igualmente también el perro extraño al que nos acercamos está dispuesto en un instante a tocar la tecla amistosa o la enemistosa y pasa fácilmente de ladrar y gruñir, a menear la cola y viceversa. Lo que funda ese fenómeno universal de filía kai neikos, es en último término la gran contraposición originaria entre la unidad de todos los seres según su ser en sí, y su total diversidad en el fenómeno, que tiene por forma el principium individuationis.

Tanto Empédocles como Schopenhauer son pensadores intuitivos, cuyas teorias del Ser incluyen aspectos anímicos 
en un discurso verosímil que da cuenta de la lucha entre fuerzas contrarias, tanto en el plano físico como en la moral, y que se representan a través de una dinámica de movimientos teóricos alternos. En Empédocles la dinámica dualista se intuye en la generación y la corrupción de los cuerpos que habitan el mundo múltiple del devenir, que se pierde y se recupera eternamente a sí mismo.

En Schopenhauer nuestro interés está más orientado a la teoría ética para aclarar su intuición de la presencia de una voluntad en la naturaleza. Así entonces la compasión se la representa como una afección misteriosa y que expresa la presencia de la voluntad de vida de la naturaleza, y trascendente al deseo egoísta del individuo. Pues lo contrario del altruismo, propio de la compasión por el no-yo, se expresa como el odio al otro y la alteridad, cuya expresión ontológica es el principio de individuación, causa profunda del egoísmo separador y efecto inmediato de la objetivación de la Voluntad en la forma de un individuo.

De otra parte, el amor y el odio se piensan en Empédocles como principios irreductibles del ser, y por lo tanto necesarios para el devenir natural. Un tanto análogo ocurre en
Schopenhauer, que piensa también al odio -y al amorcomo fuerzas necesarias para el proceso de individuación de todo ente. Podemos entonces reconocer un hilo de Ariadna que relaciona ambas visones y que tienen cosas en común, tales como:

Ambos manejan un pensamiento dialéctico, que estiman necesario para la comprensión de la necesidad de las fuerzas contrarias. Ambos discursos desarrollan intuiciones psiquicas que se proyectan en el mundo físico. Por último y a modo de conclusión afirmaría que ambas filosofías son, aunque de muy distinto modo, trascendentales en su comprensión de los primeros principios del ser y no ser, del bien y del mal, y sobre todo, enfatizaría, en su reconocimiento de la necesidad indesmentible del odio (y del amor), como fuerzas vivas, tanto en las relaciones elementales del mundo material, como en la larga vía de la auto realización de los sujetos de la moralidad. Por último, para quienes aún duermen el sueño dogmático de la bondad innata del ser humano, puede ser difícil de aceptar que debamos convivir no sólo con el mundo que amamos, sino que también lidiar con el odio metafísico que nos acecha en cada encrucijada.

\section{NOTAS}

1 El Dr. David E. Morales Troncoso es profesor de antropología filosófica y de ética, en la Universidad Diego Portales y en la Pontificia Universidad Católica de Chile, donde obtuvo su Ph.D. en el año 2000. Su área de investigación es la filosofía antigua y tiene a su haber cerca de veinte publicaciones en revistas especializadas de humanidades en Chile y Sudamérica. Además es Secretario de la revista Diadokhe y se desempeña como profesor de filosofía y ética en la Escuela Militar de Chile.

Este trabajo forma parte del Proyecto

Fondecyt N. ${ }^{\circ}$ 1070618, titulado Eros y Filosofía en la Filosofía de Sócrates (2007-2010). La primera versión de este paper fue presentada dentro del Coloquio Internacional de Antropología Filosófica, realizado entre el 11-14 de noviembre de 2008, en la Facultad de Filosofía de la Pontificia Universidad Católica de Chile.

2 El término clave aquí es Menis, que significa indignación o resentimiento violento, y que está relacionado, en el lenguaje homérico, con Cholos, la cólera áspera y amarga; se deriva también de aquí Menos, el furor guerrero propio del campo de batalla, emparentado a su vez con Thymos, nombre para el impulso emotivo que desencadena la acción (cf. Ilíada, C.V, v. 470).

3 Los artículos de fe más relevantes de los órfico pitagóricos son las creencias en la inmortalidad del Alma, en sintonía con la dinámica de la metempsicosis, y junto a ello una noción

Aceptado: 10 de enero de 2010 
cíclica del tiempo vital en conjunto con la creencia de que todos los seres vivos provienen de un trasfondo común (Cf. Porfirio, Vida de Pitágoras, ed. Gredos, 1987, p. 35). En tanto, el período cosmológico de la filosofía se caracteriza también por su interés en dar explicaciones racionales sobre el movimiento de la physis mediante argumentaciones construidas en principios causales (arjé) ya sean materiales o formales. A estos filósofos tempranos se les aplica en general el término de hilozoístas, por vincular la materia (Hyle) a la vida (Zoê) sin hacer distinciones de causas.

4 El texto crítico de Aristóteles, basado en su defensa del ordenamiento físico de las causas, reza así: "Pero puesto que resultaba evidente que en la naturaleza se da también lo contrario del bien, y que no sólo hay orden y belleza, sino también desorden y fealdad, y que los males son más abundantes que los bienes, y las cosas feas más que las bellas, he aqui que otro introdujo la Amistad y el Odio, cada uno como causa -respectivamente- de los unos y de los otros. En efecto, si se sigue y comprende, atendiendo a su pensamiento y no al modo confuso en que Empédocles se expresa, se hallará que la Amistad es la causa de los bienes y el Odio de los males. Con que seguramente acertaría quien dijera que Empédocles propuso por primera vez, el Mal y el Bien como principios, dado que la causa de todos los bienes es el Bien mismo (y la de los males, el Mal). Parece que estos se atuvieron hasta entonces, como decimos, a dos de las causas que nosotros hemos distinguido en la Física, a la materia y al de dónde (se origina el movimiento), si bien lo hicieron confusamente y sin ninguna claridad, sino como actúan en los combates los que carecen de entrenamiento", L. I, cap. 4, 985 a. Y más tarde repasa su crítica acotando que "por ejemplo Empédocles... en relación con la causa de que las cosas se muevan, si ha de ponerse una o dos, hay que reconocer que no se ha expresado ni con acierto ni con coherencia" 989 a20 (Traducción de T. Calvo, Ed. Gredos, Madrid, 1994).

5 Este ordenamiento sucesivo de las raices elementales correspondería al orden de separación de cada uno, una vez que se ha producido el inicio del ciclo cósmico fuera de la mezcla original del Esfero, pues si bien es cierto que las causas motrices cósmicas son el Amor y el Odio, cada una de las raíces, en su puridad individual, tienen un movimiento que les es propio según su naturaleza: el fuego se eleva, el aire se expande en múltiples direcciones, el agua se escurre hacia abajo siguiendo su ley de menor esfuerzo y por último la tierra representaría la inercia de permanecer quieto en una posición más bien inerte.

6 Cf. frag. 1.

7 El tratamiento crítico de la causalidad es fundamental para un lector de Kant como Schopenhauer. Sobre este punto en particular trata su famosa disertación universitaria sobre "La cuádruple raíz del principio de razón suficiente". Cf. Sciacca, Hia. de I Filosofía, ed. L. Miracle, p. 403.

8 Cf. Kritik der Kantischen Philosophie, ZA II, 516. En este texto sigo el estudio preliminar de R. Aramayo a la edición de Metafísica de las Costumbres, A. Schopenhauer, Trotta, 2001, p. xvii. 